\title{
Production of Bacterial Cellulose from Alternate Feedstocks
}

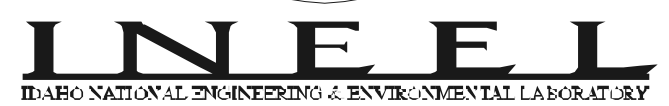

\author{
D. N. Thompson \\ M. A. Hamilton
}

May 7, 2000 - May 11, 2000

$22^{\text {nd }}$ Symposium on Biotechnology for Fuels and Chemicals
This is a preprint of a paper intended for publication in journal or proceedings. Since changes may be before publication, this preprint should not be cited reproduced without permission of the author.

This document was prepared as a account of sponsored by an agency of the United States Neither the United States Government nor any thereof, or any of their employees, makes any expressed or impli ed, or assumes any legal liability or responsibility for any third party's use, or the results such use, of any information, apparatus, product process disclosed in this report, or represents that use by such third party would not infringe privately owned rights. The views expressed in this paper not necessarily those of the U.S. Government or sponsoring agency. 


\author{
David N. Thompson ${ }^{*}$ and Melinda A. Hamilton \\ Biotechnologies Department \\ Idaho National Engineering and Environmental Laboratory \\ P.O. Box 1625 \\ Idaho Falls, ID 83415-2203 \\ ${ }^{*}$ Corresponding author.
}

\begin{abstract}
AUTHOR INFORMATION
David N. Thompson, phone: (208) 526-3977, email: thomdn@inel.gov

Melinda A. Hamilton, phone: (208) 526-0948, email:hmn@inel.gov

FAX number for all authors: (208) 526-0828
\end{abstract}

Running title: Bacterial cellulose from food process effluents

\title{
$22^{\text {nd }}$ Symposium on Biotechnology for Fuels and Chemicals Poster \#5-08 \\ Submitted May 2000
}




\title{
Production of Bacterial Cellulose from Alternate Feedstocks
}

\author{
David N. Thompson* and Melinda A. Hamilton \\ Biotechnologies Department, Idaho National Engineering and Environmental Laboratory \\ P.O. Box 1625, Idaho Falls, ID 83415-2203 \\ * Corresponding author.
}

\section{SUMMARY}

Production of bacterial cellulose by Acetobacter xylinum ATCC 10821 and 23770 in static cultures was tested from unamended food process effluents. Effluents included low- and high-solids potato effluents (LS \& HS), cheese whey permeate (CW), and sugar beet raffinate (CSB). Strain 23770 produced 10\% less cellulose from glucose than did 10821, and diverted more glucose to gluconate. Unamended HS, $\mathrm{CW}$, and CSB were unsuitable for cellulose production by either strain, while LS was unsuitable for production by 10821 . However, 23770 produced 17\% more cellulose from LS than from glucose, indicating unamended LS could serve as a feedstock for bacterial cellulose.

KEYWORDS Bacterial cellulose, Acetobacter xylinum, potato effluent, beet raffinate, whey permeate

\section{INTRODUCTION}

Bacterial cellulose has significant advantages over plant cellulose. Bacterial cellulose fibrils are randomly oriented and the product is highly amorphous $(1,2)$. It is generated as a never-dried membrane in a nearly pure form (3) which contains $99.1 \mathrm{wt} \%$ water, of which $0.3 \mathrm{wt} \%$ is bound and $98.8 \mathrm{wt} \%$ is free water (4). It has more than 200 times greater surface area than isolated softwood cellulose (1), and has a tensile strength similar to that of steel (5). Many potential high value markets exist for thin film bacterial cellulose, including acoustic diaphragms (6), artificial skin (7,8), artificial blood vessels (9), liquid loaded medical pads (10), super-sorbers (11), and specialty membranes (12). Potential markets for bacterial cellulose produced as pellets in agitated culture include the mining industry, the oil industry, foods, and the pulp and paper industry $(1,2)$.

The most studied producer of bacterial cellulose is Acetobacter xylinum (13), a Gram-negative, obligately aerobic bacterium $(10,14,15)$. The optimum $\mathrm{pH}$ for cellulose production is $5.0(13,16)$, and 
production is associated with and proportional to growth (17). Cellulose production has been demonstrated from glucose, sucrose, fructose, glycerol, mannitol, arabitol, and many other substrates $(5,13,16,18)$. Excess glucose is oxidized to gluconate in wild-type A. xylinum, which lowers the $\mathrm{pH}$ and inhibits cellulose production (13). Genetically altered strains with substantially reduced ability to form gluconate have been developed (5). Methionine and lactate stimulate cell growth in the early stages, allowing higher rates of cellulose production (19).

Low production rates and high medium costs limit commercial use of bacterial cellulose (3). We report testing of unamended food process effluents, which typically represent economical and environmental liabilities to the producers, as substrates for bacterial cellulose production in static culture.

\section{METHODS}

Food process effluents. Potato effluents, cheese whey permeate (CW), and concentrated sugar beet raffinate (CSB) were obtained from Idaho processing plants. Two potato process effluents were tested, including high-solids (HS) and low-solids (LS) effluents. To lower carbohydrate concentrations to levels similar to the control medium (described below), the effluents were diluted with distilled water. HS effluent was diluted 1:10 by weight, while LS effluent, CW, and CSB were diluted 1:10 by volume. Each diluted effluent was autoclaved at $121{ }^{\circ} \mathrm{C}$ for 20 minutes, and the $\mathrm{pH}$ was adjusted to 5.0 with $\mathrm{HCl}$ prior to use. Control experiments were conducted using an optimized glucose medium containing $20 \mathrm{~g} / \mathrm{L}$ glucose, $5 \mathrm{~g} / \mathrm{L}$ yeast extract, $5 \mathrm{~g} / \mathrm{L}$ peptone, $2.7 \mathrm{~g} / \mathrm{L} \mathrm{Na}_{2} \mathrm{HPO}_{4}$, and $1.15 \mathrm{~g} / \mathrm{L}$ citrate, $\mathrm{pH} 5.0$ (Schramm and Hestrin's medium) $(15,20)$. Initial carbohydrate data for the control and the diluted effluents are presented in Table 1.

Cultures and Maintenance. Acetobacter xylinum 10821 and 23770 were obtained from the American Type Culture Collection (ATCC, Manassas, VA). Several generations were grown in $25 \mathrm{~g} / \mathrm{L}$ mannitol, 5 $\mathrm{g} / \mathrm{L}$ yeast extract, and $3 \mathrm{~g} / \mathrm{L}$ peptone, $\mathrm{pH} 5.0$ (21). Reference cultures were maintained at $4{ }^{\circ} \mathrm{C}$ on malt agar slants containing Schramm and Hestrin's medium (15,20) and $15 \mathrm{~g} / \mathrm{L}$ agar (Difco), and were subcultured monthly. Frozen seed stocks were prepared as follows. The cellulose pellicle was removed 
from the reference slant with sterile distilled water, vortexed for $5 \mathrm{~min}$, and sonicated for $20 \mathrm{~min}$ to remove the cells from the pellicle. The pellicle was removed, the liquid added to $500 \mathrm{~mL}$ of Schramm and Hestrin's medium and cultured with occasional gentle mixing for 7-14 days at $30^{\circ} \mathrm{C}$, until the cell number exceeded $2 \times 10^{8}$ cells $/ \mathrm{mL}$. Cells were then removed from the resulting pellicle by vortexing and sonication, and $10 \mathrm{~mL}$ aliquots of the culture liquid were frozen at $-80^{\circ} \mathrm{C}$ in $15 \mathrm{vol} \%$ glycerol as previously described (21).

Experimental. Experiments were conducted in static $100 \mathrm{~mm}$ storage dishes (Fisher, Cat. No. 08-782) containing $100 \mathrm{~mL}$ of medium. Abiotic controls contained Schramm and Hestrin's medium and were not inoculated, while biotic controls were prepared as follows. Frozen seed stocks were thawed and added at $10 \mathrm{~mL}$ per $250 \mathrm{~mL}$ of Schramm and Hestrin's medium (15,20). The cultures were grown as described above for preparation of seed cultures. When the cell number exceeded $2 \times 10^{8}$ cells $/ \mathrm{mL}$, cells were removed from the pellicle and inoculated into a large excess of Schramm and Hestrin's medium to give $1 \times 10^{7}$ cells $/ \mathrm{mL}$. The medium was mixed well and transferred in $100 \mathrm{~mL}$ aliquots to sterile $100 \mathrm{~mm}$ dishes. All controls were incubated at $30^{\circ} \mathrm{C}$ for 14 days. For each medium, this amounted to sixteen separate cultures, all starting at the same conditions and inoculum size. Two of these cultures were sacrificed every second or third day, and analyzed for substrate, cell numbers, $\mathrm{pH}$, cellulose weight, and pellicle thickness. This was done because measurement of cellulose weight and cell counts required disruption of the static culture and removal of the cells from the pellicle. Therefore, data at each time point presented below are averages from separate cultures. Experiments utilizing unamended effluents were conducted as above, except the final transfer was completed using the autoclaved, diluted $\mathrm{pH} 5.0$ effluent medium.

\section{Analytical methods.}

Cell numbers \& pH. Cells were removed from the pellicle using the procedure described above. Cell numbers were then determined by direct count of $5 \mu \mathrm{L}$ of culture fluid on a Petroff-Hauser hemocytometer slide (average of 10 separate counts). Liquid samples were then taken for substrate analyses and for cell counts. $\mathrm{pH}$ was measured using a standard $\mathrm{pH}$ probe and meter. 
Substrate concentrations. Samples were measured for substrate levels after filtering through a 0.22 $\mu \mathrm{m}$ polysulfone membrane filter to remove cells and cellulose fibers. Glucose, sucrose, and lactose were measured using a YSI Model 6200 Glucose Analyzer (Yellow Springs Instrument, Yellow Springs, OH) fitted with the appropriate membrane(s) (glucose, sucrose, and lactose; catalog numbers 2365, 2703, and 2702, respectively), buffers, and standard solutions. Soluble starch was estimated after removal of cells and particulates as previously described (22), using the phenol-sulfuric acid assay for total carbohydrates (23). For potato effluent cultures, an aliquot of well-mixed culture fluid was filtered through a tared cellulose filter paper (Fisher P8, average pore size $20 \mu \mathrm{m}$ ) and insolubles were estimated by weight difference after drying to constant weight at $105^{\circ} \mathrm{C}$.

Pellicle weight and thickness. Cellulose pellicle thickness was measured without removal of the absorbed water present in the pellicle at harvest. The pellicle was placed onto a smooth, flat board and spread out. The thickness was measured at three different positions around the periphery to the nearest $0.5 \mathrm{~mm}$, and the values averaged. The pellicle was then placed into $300 \mathrm{~mL}$ of $2 \mathrm{wt} \% \mathrm{NaOH}$ and autoclaved for $20 \mathrm{~min}$ at $121{ }^{\circ} \mathrm{C}$. After cooling, the pellicle was neutralized with dilute $\mathrm{H}_{2} \mathrm{SO}_{4}$ and washed by filtration (Fisher P8 filter paper) until the filtrate was $\mathrm{pH}$ 7-7.5. The pellicle was then collected by filtration on a tared filter paper and dried to constant weight at $105{ }^{\circ} \mathrm{C}$.

\section{RESULTS}

Strain comparison. Data from 14-day control cultures of A. xylinum 10821 and 23770 are shown in Figures 1 and 2, respectively. Glucose consumption by 23770 was much more rapid that that observed for 10821 , with essentially all of the glucose gone in 9 days. Only $37 \%$ of the glucose was consumed by 10821 in the same period, and only $64 \%$ was consumed by 14 days. Growth rates for both strains were essentially the same over the course of the experiment. The $\mathrm{pH}$ of the 23770 cultures dropped to 3.2 after 4 days of culture, while 10821 cultures slowly decreased to $\mathrm{pH} 4.5$. Cellulose production was similar for the two strains over the initial 4 days of culture, at which time both strains had produced 220-280 mg of cellulose. Linear production was observed after the $4^{\text {th }}$ day for 10821 , to $550 \mathrm{mg}$ on day 14 . Strain 
23770 reached $450 \mathrm{mg}$ on day 7 , after which only $50 \mathrm{mg}$ more cellulose was produced. Overall cellulose production was better from 10821, with $11 \%$ higher cellulose produced in 14 days.

Net cellulose production rates and yields from glucose are presented in Table 2. Cellulose production rates were initially high for 10821, but decreased slowly over time to a production rate of 5.0 g cellulose $/ \mathrm{d} / \mathrm{m}^{2}$ of surface and a yield of $53 \%$ after 14 days. For 23770 , the glucose was essentially depleted after 7 days, at which point the net production rate was $8.1 \mathrm{~g} / \mathrm{d} / \mathrm{m}^{2}$ and the yield was $28 \%$. After 14 days, the net production rate was $4.5 \mathrm{~g} / \mathrm{d} / \mathrm{m}^{2}$, with an average production rate of $5.2 \mathrm{~g} / \mathrm{d} / \mathrm{m}^{2}$ after day 7 . Cellulose production from effluents. Cell growth data, culture $\mathrm{pH}$, and cellulose production data for the unamended effluents are shown in Table 3. Control data are included for comparison. Growth was observed in all media. Cell numbers in the potato effluent cultures were an order of magnitude higher than those observed in the other effluents or in the control, which was found to be from spores in the effluent that survived the autoclaving (22). Some contaminating cells that survived the autoclaving step were also seen in the other effluent media, but these cells did not seem to grow as well at pH 5.0 as those in the potato effluents.

There were also differences in the trends of culture $\mathrm{pH}$ between the two strains. For 10821, there was a general slight decrease in $\mathrm{pH}$ to the 4.0-4.5 range for $\mathrm{HS}$ and $\mathrm{CW}$, while the $\mathrm{pH}$ of the LS culture was essentially unchanged. In the CSB culture, the $\mathrm{pH}$ increased to about 7.5 over the 14 days. For 23770, the $\mathrm{pH}$ increased in all media except $\mathrm{CW}$, for which it did not change significantly. The largest increase was for the LS effluent, to $\mathrm{pH}$ 7.3. This is in stark contrast to the glucose control, which decreased to $\mathrm{pH} 3.2$ over the 14 days.

Comparison of the cellulose production data in Table 3 indicate that neither strain was capable of producing significant bacterial cellulose from unamended $\mathrm{HS}, \mathrm{CSB}$, or CW. Values from replicate sacrificed cultures were somewhat scattered, but in all cases, very little cellulose was produced from these unamended effluents. The maximum amounts of cellulose produced in any of the sacrificed cultures utilizing these diluted effluents by 10821 were 22,33 , and $4 \mathrm{mg}$ of cellulose from HS, CSB, and $\mathrm{CW}$, respectively. Comparatively, 23770 produced maximum amounts of 84,19 , and $113 \mathrm{mg}$ of 
cellulose from the same media. Results with diluted LS effluent were markedly different for the two strains. A maximum $95 \mathrm{mg}$ of cellulose was produced by 10821 , while 23770 produced up to $580 \mathrm{mg}$ of cellulose from LS in 14 days. This amounts to an estimated cellulose yield from diluted LS effluent of about $30 \%$, which is nearly the same yield as that obtained by 23770 from optimized glucose medium.

\section{DISCUSSION}

Strain comparison. Cell growth on Schramm and Hestrin's medium was similar for the two strains, but 23770 consumed the glucose much more quickly. The rapid utilization of glucose and the drop in $\mathrm{pH}$ observed for 23770 suggests the excess glucose was converted to gluconate. Excess glucose not used for cellulose synthesis is oxidized by A. xylinum to gluconate (13). This allows some accumulation of gluconate, which can lower the $\mathrm{pH}$ and inhibit cellulose production at high glucose concentrations (13).

Forng et al. (24) demonstrated that glucose concentrations above about $1 \%$ give relatively smaller increases in cellulose produced, while Masaoka et al. (13) observed no difference in the rate of cellulose production from $0-2 \%$ glucose, with inhibition observed at $4 \%$ glucose. Strain 23770 produced cellulose at a markedly higher initial rate than 10821, but at only about half the yield. When initial carbon source concentrations below $2 \mathrm{wt} \%$ are used, a production efficiency of $45 \%$ (weight of cellulose per carbon source consumed) can be obtained (25). This magnitude was observed for 10821 (48\% on the same basis), but not for 23770 (27\%). After the glucose was consumed in 23770 cultures, a low rate of cellulose production continued. This production was likely from the citrate in the medium, since it has been shown that citrate is eventually used as a carbon source for growth and cellulose production, but only after the glucose is consumed (26). In this study, overall cellulose production from glucose was better from 10821, with $11 \%$ higher cellulose produced in 14 days.

Cellulose production from effluents. All of the food process effluents were able to support growth of both strains of A. xylinum, and at least limited cellulose production. From HS (insoluble starch), LS (starch), CSB (sucrose), and CW (lactose), 10821 produced 4\%, 17\%, 6\%, and $0.8 \%$, respectively, of the cellulose produced in its glucose control. Strain 23770 produced $17 \%, 117 \%, 4 \%$, and $23 \%$ of the 
cellulose in its glucose control from the same media. For comparison, Matsuoka et al. (13) showed 18\%, $33 \%$, and $16 \%$ yields of bacterial cellulose from starch, sucrose, and lactose, respectively, relative to glucose (100\%). Their experiments (13) consisted of 3 day cultures of A. xylinum IFO 13693 on a basic medium consisting of $2 \%$ peptone, $0.5 \%$ yeast extract, $0.5 \%$ glucose, $0.1 \% \mathrm{MgSO}_{4} \bullet 7 \mathrm{H}_{2} 0$, and $0.2 \%$ ethanol, pH 6.0. Glucose was simply replaced by the other carbon sources for the tests.

We cannot make a direct comparison of the HS medium results with those of Matsuoka et al. (13), since although it is not specifically stated, we have assumed that their starch substrate was likely soluble. From the LS medium, our results show poorer than expected cellulose yields with 10821, and much better than expected cellulose yields with 23770. Our results with the CSB effluent are much lower than those reported from sucrose by Matsuoka et al. (13), which may be due to the presence of toxic heavy metals in the CSB (27). Finally, cellulose yields from CW effluent were very low from 10821 and about what was expected for 23770. Of the unamended, diluted effluents tested, only the LS effluent medium supported substantial cellulose production, and only by 23770 .

Given the similarities between cell numbers and overall cellulose production by the two strains on Schramm and Hestrin's medium, it is not immediately clear to the authors why 10821 was unable to produce substantial cellulose from the LS medium. The most quantifiable differences between the two cultures on LS medium, other than cellulose production, are the different trends of $\mathrm{pH}$. The LS effluent is known to contain indigenous bacteria as received from the processor (22). Some of these bacteria survived the autoclaving step and were present in the LS cultures, as evidenced by the much higher cell numbers observed, and by uninoculated controls (not shown). These bacteria are known to lower medium $\mathrm{pH}$ to 4.0 if left unchecked (22), suggesting that they are facultatively fermentative bacteria. Since they are indigenous to the potato effluents, they would be expected to possess an amylase system and to convert starch to glucose. This would help to increase cellulose yields from the starch in the effluent through supplementation of the ability of A. xylinum to convert starch to glucose.

In addition, $\mathrm{pH}$ in the 23770 culture on LS medium did not drop as it did in pure culture on glucose medium. This suggests that indigenous bacteria consumed the gluconate as it was being 
produced. Removal of the gluconate would minimize its inhibitory effects on cellulose production. Gluconate, which is not a substrate for cellulose production, may have been converted to smaller organic acids, which both stimulate (28) and serve as substrates (13) for cellulose production. The 10821 culture, which did not produce significant amounts of gluconate (as evidenced by the lack of a drop in $\mathrm{pH}$ on glucose medium) would not experience this benefit, since the gluconate would not have been present for indigenous bacteria to consume. The observed $\mathrm{pH}$ increase could then be due to consumption of the organic acids in the unbuffered LS medium. While not a part of the scope of this study, these possibilities should be examined as they suggest a synergistic mixed culture strategy for production of bacterial cellulose from LS effluent.

Since it has been shown that A. xylinum can produce cellulose from a myriad of carbon sources (13), it is likely that medium additions could be made that would allow higher cellulose production from each of the effluents. Pretreatments of the effluents could be done in order to increase free carbohydrate concentrations, or to remove potentially toxic components such as heavy metals in sugar beet molasses (27). In addition, it is probable that contaminating bacteria already present in the effluents also serve to lower yields, since all of the media contained indigenous bacteria that were resistant to heat sterilization by autoclaving.

Since medium costs limit commercial production of bacterial cellulose in static cultures (3), it is important to minimize carbon, nutrient, and energy additions wherever possible. Thus it is generally undesirable to make medium additions, to use pretreatments, or to use extensive or energy-intensive sterilization procedures beyond the absolute minimum required. The estimated yield of cellulose from unamended, diluted LS effluent by 23770 was not significantly different from that on Schramm and Hestrin's medium. This was true even though substantial glucose was diverted to gluconate and the expected yield from starch is only $18 \%$ of that from glucose. This suggests that A. xylinum 23770 is more suitable than 10821 for production of bacterial cellulose from LS. 


\section{CONCLUSIONS}

A diluted, unamended low-solids potato process effluent was found to support substantial production of bacterial cellulose by Acetobacter xylinum ATCC 23770 in static culture. Diluted, unamended highsolids potato effluent, cheese whey permeate, and sugar beet raffinate did not support significant cellulose production by either A. xylinum 10821 or 23770 . A. xylinum 10821 , while diverting much less glucose to gluconate than 23770 , was unable to produce a significant amount of cellulose from the lowsolids effluent medium. Since the yield of cellulose by A. xylinum 23770 was the same from diluted, unamended low-solids potato process effluent and from optimized Schramm and Hestrin's medium, this strain is more appropriate to use for cellulose production from this effluent.

\section{ACKNOWLEDGEMENTS}

This work was supported through the Laboratory Directed Research \& Development Program at the Idaho National Engineering and Environmental Laboratory under DOE Idaho Operations Office Contract DE-AC07-99ID13727.

\section{REFERENCES}

1. Krieger, J. (1990), Chem. Eng. News. 68,35-37.

2. Johnson, D.C. and Winslow, A.R. (1990), Pulp \& Paper. May 1990, 105-107.

3. Brown, R.M., Jr. (1989), in Cellulose: Structural and Functional Aspects. Kennedy, J.F., Phillips, G.O., and Williams, P.A., Ellis Horwood Ltd, Chichester. Chapter 16, 145-151.

4. Okiyama, A., Motoki, M., and Yamanaka, S. (1992), Food Hydrocoll. 6, 479-487.

5. Ross, P., Mayer, R., and Benziman, M. (1991), Microbiol. Rev. 55, 35-58.

6. Nishi, Y., Uryu, M., Yamanaka, S., Watanabe, K., Kitamura, N., Iguchi, M., and Mitsuhashi, S. (1990), J. Mater. Sci. 25, 2997-3001. 
7. Fontana, J.D., de Souza, A.M., Fontana, C.K., Torriani, I.L., Moreschi, J.C., Gallotti, B.J., de Souza, S.J., Narcisco, G.P., Bichara, J.H., and Farah, L.F.X. (1990), Appl. Biochem. Biotechnol. 24/25, $253-$ 264.

8. Farah, L.F.X. (1990), U.S. Patent 4,912,049.

9. Yamanaka, S., Ono, E., Watanabe, K., Kusakabe, M., and Suzuki, Y. (1990), European Patent Application EP 0396344.

10. Ring, D.F., Nashed, W., and Dow, T. (1986), U.S. Patent 4,588,400.

11. Chatterjee, P.K. (1989), in Cellulosics Utilization: Research and Rewards in Cellulosics. Inagaki, H. and Phillips, G.O., eds., Proc. Nisshinbo Int. Conf. on Cellulosics Utilization in the Near Future, Tokyo, Japan, December 5-6, 1988, Elsevier Science Publishing Co., Inc. New York, 12-17.

12. Shibazaki, H., Kuga, S., Onabe, F., and Usuda, M. (1993), J. Appl. Polym. Sci. 50, 965-969.

13. Masaoka, S., Ohe, T., and Sakota, N. (1993), J. Ferment. Bioeng. 75, 18-22.

14. Zaar, K. (1979), J. Cell Biol. 80, 773-777.

15. Watanabe, K. and Yamanaka, S. (1995), Biosci. Biotechnol. Biochem. 59, 65-68.

16. Oikawa, T., Morino, T., and Ameyama. M. (1995), Biosci. Biotechnol. Biochem. 59, 1564-1565.

17. Ishikawa, A., Matsuoka, M., Tsuchida, T., and Yoshinaga, F. (1995), Biosci. Biotechnol. Biochem. 59, 2259-2262.

18. Oikawa, T., Ohtori, T., and Ameyama, M. (1995), Biosci. Biotechnol. Biochem. 59, 331-332.

19. Matsuoka, M., Tsuchida, T., Matsushita, K., Adachi, O., and Yoshinaga, F. (1996), Biosci. Biotechnol. Biochem. 60, 575-579.

20. Schramm, M. and Hestrin, S. (1954), J. Gen. Microbiol. 11, 123-129.

21. Gherna, P. (1989), in American Type Culture Collection Catalogue of Bacteria and Phages. $17^{\text {th }}$ Ed., 403.

22. Thompson, D.N., Fox, S.L., and Bala, G.A. (2000), Appl. Biochem. Biotechnol., 84-86, in press.

23. Gerhardt, P., Murray, R.G.E., Wood, W.A., and Krieg, N.R., eds. (1994), in Methods for General and Molecular Bacteriology, American Society for Microbiology, Washington, D.C., pp. 518-519. 
24. Forng, E.R., Anderson, S.M., and Cannon, R.E. (1989), Appl. Environ. Microbiol., 55,1317-1319.

25. De Wulf, P., Joris, K., and Vandamme, E.J. (1996), J. Chem. Technol. Biotechnol., 67,376-380.

26. Geyer, U., Klemm, D., and Schmauder, H.-P. (1994), Acta Biotechnol. 14, 261-266.

27. Roukas, T. (1998), Process Biochem., 33, 805-810.

28. Dudman, W.F. (1959), J. Gen. Microbiol., 21, 327-337. 


\section{TABLES}

Table 1: Typical initial carbohydrate data for the control medium and for diluted high-solids (HS) and low-solids (LS) potato effluents, diluted sugar beet raffinate (CSB), and diluted cheese whey permeate (CW). Effluents varied slightly between batches obtained from the food processing plants.

\begin{tabular}{|c|c|c|c|c|c|}
\hline \multirow[b]{3}{*}{ Carbohydrate } & \multicolumn{5}{|c|}{ COMPOSITION (wt\%) } \\
\hline & \multirow{2}{*}{$\begin{array}{l}\text { Control } \\
\text { Medium }\end{array}$} & \multicolumn{4}{|c|}{ 1:10-diluted Effluents } \\
\hline & & $\overline{\mathrm{HS}}$ & $\overline{\mathrm{LS}}$ & $\mathrm{CSB}^{\mathrm{a}}$ & $\overline{\mathrm{CW}}$ \\
\hline Glucose & 2.0 & 0.002 & 0.04 & 0.04 & 0.19 \\
\hline Sucrose & $--^{b}$ & --- & --- & 2.2 & --- \\
\hline Lactose & --- & --- & --- & --- & $1.3^{\mathrm{c}}$ \\
\hline Soluble starch & --- & 0.47 & 1.5 & --- & --- \\
\hline Insolubles $^{\mathrm{d}}$ & --- & 1.6 & 0.66 & --- & --- \\
\hline
\end{tabular}

\footnotetext{
a Although not measured, sugar beet raffinate also contains minute amounts of raffinose and fructose.

b None.

c This value includes small amounts of galactose.

d Insolubles includes starch and non-starch components. Insoluble starch accounted for up to $85 \%$ of the insolubles in both HS and LS, depending on the particular batch from the processor.
} 
Table 2: Cellulose production rates and yields for the glucose control cultures of Acetobacter xylinum 10821 and 23770.

\begin{tabular}{|c|c|c|c|c|}
\hline \multirow[b]{3}{*}{ Day } & \multicolumn{2}{|c|}{ Acetobacter xylinum 10821} & \multicolumn{2}{|c|}{ Acetobacter xylinum 23770} \\
\hline & Net Production & & Net Production & \\
\hline & $\operatorname{Rate}\left(\mathrm{g} / \mathrm{d} / \mathrm{m}^{2}\right)^{\mathrm{a}}$ & Yield $(\%)^{b}$ & Rate $\left(\mathrm{g} / \mathrm{d} / \mathrm{m}^{2}\right)$ & Yield $(\%)$ \\
\hline 0 & 0.0 & 0.0 & 0.0 & 0.0 \\
\hline 2 & 0.69 & 0.0 & 0.09 & 0.6 \\
\hline 4 & $8.93^{\mathrm{c}}$ & $128.6^{\mathrm{c}}$ & 7.00 & 17.5 \\
\hline 7 & 6.84 & 84.4 & 8.06 & 27.9 \\
\hline 9 & 6.19 & 74.2 & 5.68 & 24.6 \\
\hline 11 & 4.45 & 51.0 & 5.49 & 28.9 \\
\hline 14 & 5.00 & 53.4 & 4.51 & 30.1 \\
\hline
\end{tabular}

a Net production rates (g cellulose $/ \mathrm{d} / \mathrm{m}^{2}$ of surface) were each calculated from time zero.

b Yield is defined as: $(\mathrm{g}$ cellulose produced $) /(\mathrm{g}$ glucose consumed $) \times(180 / 162) \times 100 \%$. The ratio $180 / 162$ accounts for the loss of one water molecule per glucose molecule as the glucose is polymerized to cellulose.

c These values are indicative of measurement error in dry weights for samples containing very small amounts of cellulose. 
Table 3: Culture data for production of bacterial cellulose from diluted unamended high-solids (HS) and low-solids (LS) potato effluents, diluted unamended sugar beet raffinate (CSB), and diluted unamended cheese whey permeate $(\mathrm{CW})$.

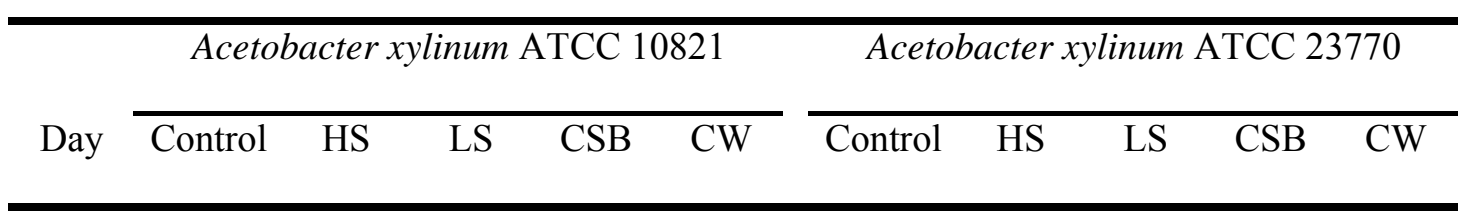

\section{$\underline{\text { Cell counts }\left(\times 10^{-7} \text { cells } / \mathrm{mL}\right)}$}

\begin{tabular}{lllllllllll}
0 & 1.66 & 2.19 & 1.31 & 1.30 & 1.78 & 1.78 & 2.07 & 1.26 & 2.07 & 1.83 \\
2 & 2.33 & 17.8 & 6.25 & 3.84 & 3.88 & 2.11 & 22.3 & 6.48 & 3.06 & 4.28 \\
5 & 5.84 & 44.6 & 16.7 & 4.34 & 5.09 & 5.55 & 32.8 & 23.3 & 8.80 & 7.00 \\
7 & 5.92 & 38.7 & 13.8 & 5.13 & 6.70 & 5.78 & 15.5 & 20.7 & 4.38 & 6.70 \\
9 & 5.36 & 45.4 & 47.3 & 8.72 & 5.08 & 6.02 & 43.1 & 48.9 & 9.05 & 8.56 \\
12 & 6.48 & 67.8 & 29.6 & 5.00 & 14.4 & 6.39 & 58.8 & 25.1 & 5.27 & 17.1 \\
14 & 6.91 & 58.9 & 32.8 & 15.6 & 4.02 & 5.31 & 70.8 & 32.3 & 8.86 & 6.73 \\
\hline
\end{tabular}

\section{Culture pH}

\begin{tabular}{lllllllllll}
0 & 5.00 & 5.00 & 5.00 & 5.00 & 5.00 & 5.00 & 5.00 & 5.00 & 5.00 & 5.00 \\
2 & 4.78 & 3.87 & 4.87 & 5.29 & 4.15 & 3.85 & 3.62 & 4.59 & 5.21 & 3.70 \\
5 & 4.73 & 4.02 & 4.96 & 5.32 & 4.18 & 3.16 & 4.63 & 4.85 & 5.27 & 4.37 \\
7 & 4.78 & 4.13 & 4.91 & 5.26 & 3.96 & 3.22 & 5.56 & 5.10 & 5.29 & 4.62 \\
9 & 4.78 & 4.64 & 6.05 & 5.79 & 4.03 & 3.34 & 5.39 & 5.62 & 5.39 & 4.92 \\
12 & 4.61 & 4.76 & 5.31 & 7.24 & 4.01 & 3.29 & 5.84 & 7.14 & 5.32 & 4.95 \\
14 & 4.48 & 4.65 & 5.09 & 7.45 & 3.93 & 3.19 & 5.65 & 7.27 & 5.28 & 4.87 \\
\hline
\end{tabular}

\section{Mass of cellulose produced (mg)}

$\begin{array}{lllllllllll}0 & 0.00 & 0.00 & 0.00 & 0.00 & 0.00 & 0.00 & 0.00 & 0.00 & 0.00 & 0.00 \\ 2 & 10.9 & 19.1 & 0.00 & 2.40 & 0.00 & 1.40 & 1.76 & 17.4 & 0.00 & 7.05\end{array}$




\begin{tabular}{ccccccccccc}
5 & 281 & 21.5 & 36.4 & 1.15 & 2.15 & 220 & 84.4 & 335 & 6.00 & 108 \\
7 & 376 & 0.00 & 28.8 & 0.00 & 1.65 & 443 & 0.00 & 553 & 0.400 & 97.7 \\
9 & 437 & 0.00 & 94.6 & 9.55 & 0.45 & 401 & 0.00 & 498 & 18.6 & 17.7 \\
12 & 385 & 13.5 & 35.1 & 30.3 & 4.15 & 474 & 26.9 & 483 & 18.1 & 17.6 \\
14 & 550 & 0.00 & 48.4 & 33.0 & 1.30 & 496 & 25.9 & 581 & 0.700 & 113 \\
\hline
\end{tabular}




\section{FIGURE LEGENDS}

Figure 1: Culture data for 14-day stationary control cultures of Acetobacter xylinum ATCC 10821.

Each data point represents the average of duplicate sacrificed cultures. Symbols are: ( $\square$ ) cell number; (ם) glucose; $(\boldsymbol{\Delta})$ dry weight of the cellulose pellicle; and $(\Delta) \mathrm{pH}$.

Figure 2: Culture data for 14-day stationary control cultures of Acetobacter xylinum ATCC 23770. Each data point represents the average of duplicate sacrificed cultures. Symbols are: ( $\square$ ) cell number; (匹) glucose; $(\boldsymbol{\Delta})$ dry weight of the cellulose pellicle; and $(\Delta) \mathrm{pH}$. 


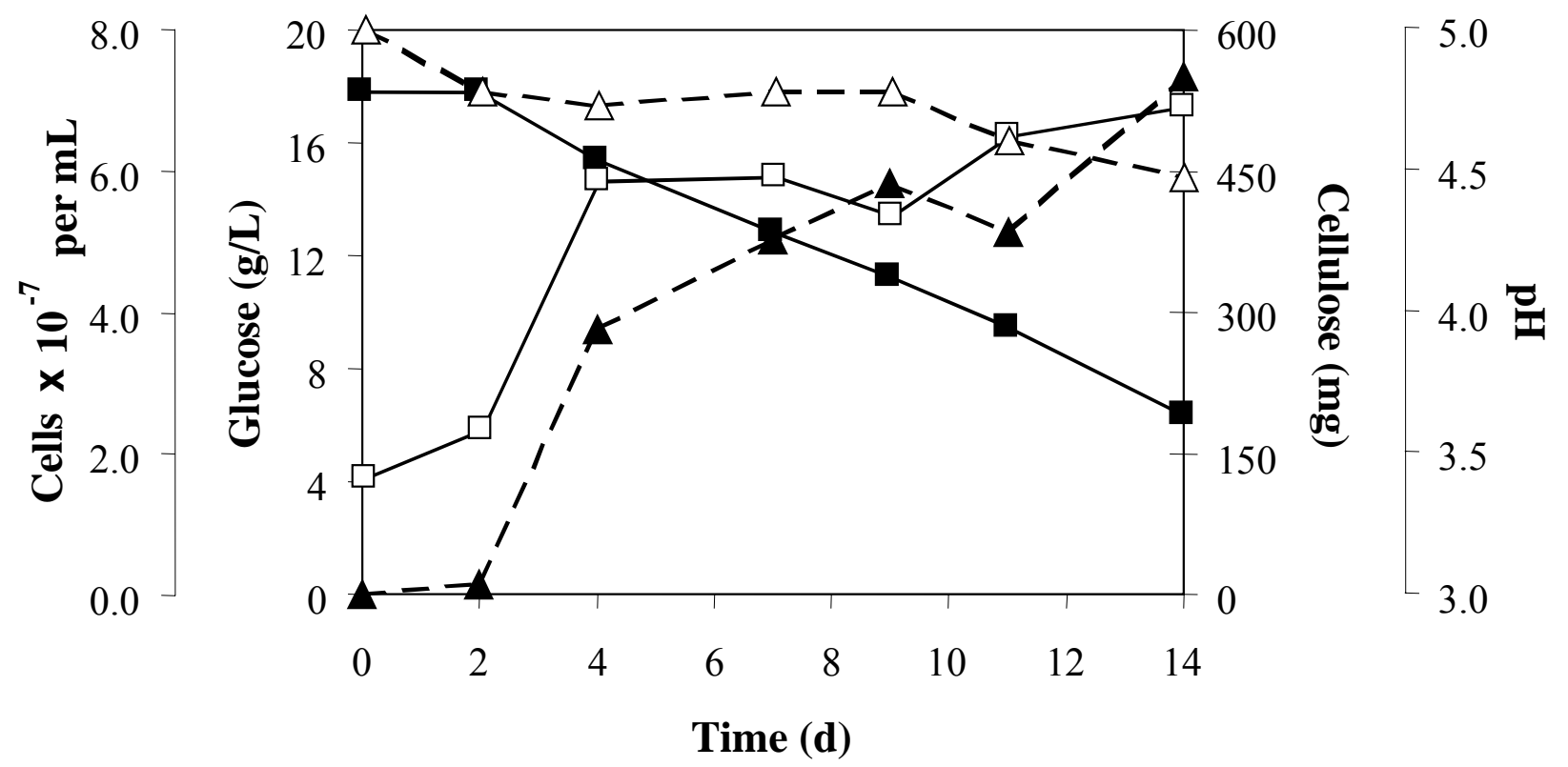

FIGURE 1 - THOMPSON AND HAMILTON 


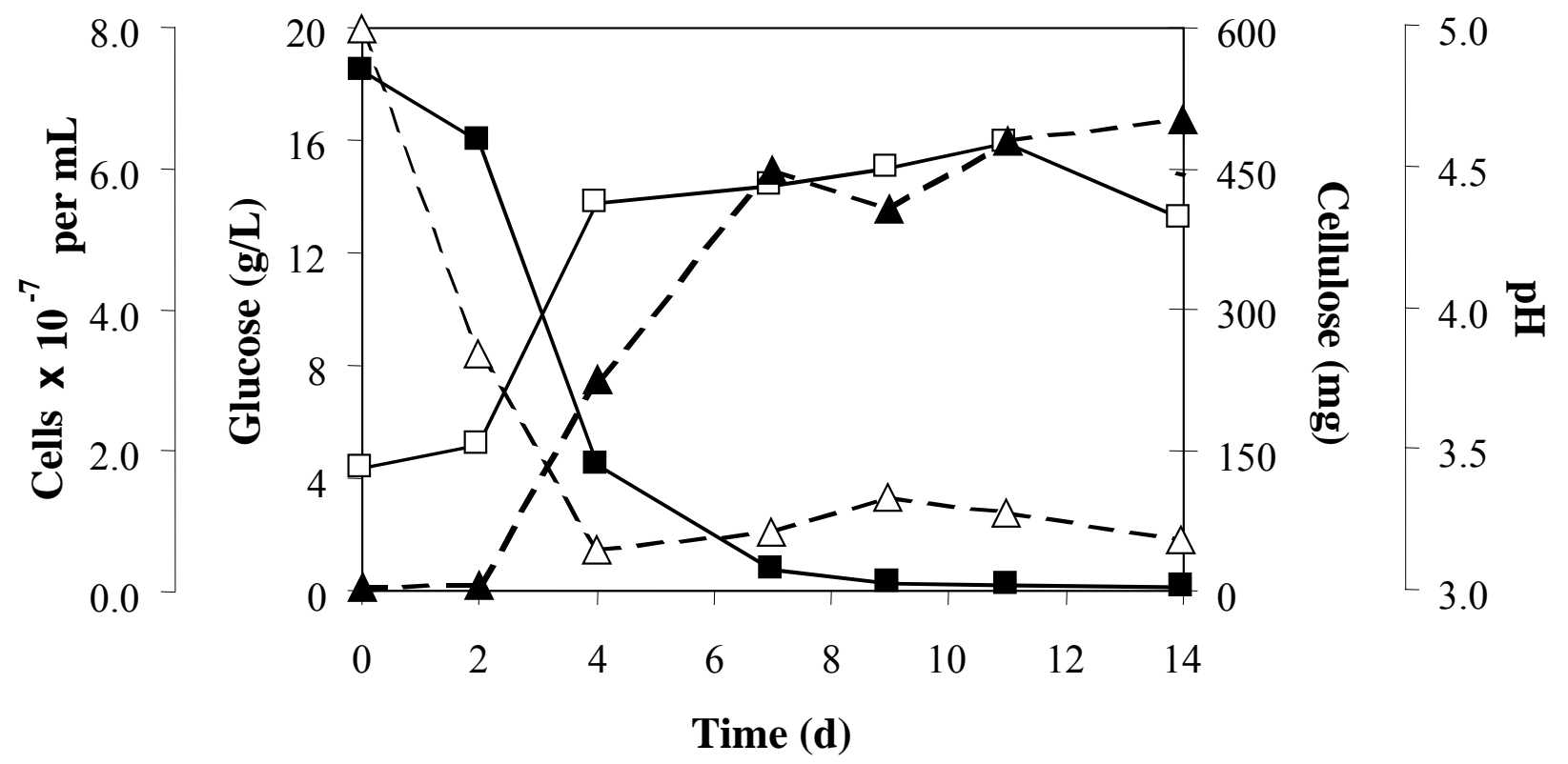

FIGURE 2 - THOMPSON AND HAMILTON 